\title{
Investigating effects of preoperative inflammatory biomarkers on predicting survival outcomes of peripheral intrahepatic cholangiocarcinoma after curative resection
}

\author{
Zeyu Zhang \\ Xiangya Hospital Central South University \\ Yufan Zhou \\ Xiangya Hospital Central South University \\ Kuan Hu \\ Xiangya Hospital Central South University \\ Yun Huang ( $\nabla$ huangyun-1002@163.com ) \\ xiangya hospital central south university
}

Research

Keywords: intrahepatic cholangiocarcinoma, inflammatory biomarker, systemic immune-inflammation index

Posted Date: August 4th, 2020

DOI: https://doi.org/10.21203/rs.3.rs-52318/v1

License: (c) (i) This work is licensed under a Creative Commons Attribution 4.0 International License.

Read Full License 


\section{Abstract}

Introduction: Intrahepatic cholangiocarcinoma (ICC) stands as the second most common malignant tumor in liver with poor patient prognosis. Increasing evidences have shown that inflammation plays a significant role in tumor progression, angiogenesis and metastasis. However, the prognosis significance of inflammatory biomarkers on recurrence-free survival (RFS) and overall survival (OS) in peripheral ICC patients is poorly recognized.

Methods: Peripheral ICC patients who underwent curative hepatectomy and diagnosed pathologically were retrospectively analyzed. Inflammatory biomarkers, including neutrophil-to-lymphocyte ratio (NLR), platelet-to-lymphocyte ratio (PLR), lymphocyte-to-monocyte ratio (LMR), systemic immune-inflammation index (SII), were investigated.

Results: Receiver operating characteristic (ROC) curves showed no significance in NLR, PLR and LMR in RFS and OS, while significant results were shown on SIl in both RFS $(P=0.035)$ and $O S(P=0.034)$ with areas under ROC curve as $0.63(95 \% \mathrm{Cl}: 0.52-0.74)$ and 0.62 (95\% Cl: $0.51-0.72)$, respectively. Kaplan-Meier curves revealed statistically significant better survival data in SII-low groups on both RFS (P®0.001) and OS (Pख0.001). The univariate and multivariate analyses revealed that higher level of SIl was independently associated with both poorer RFS time and OS time. However, no significant result was shown on NLR, PLR or LMR.

Conclusion: SII is an effective prognostic factor for predicting the prognosis of peripheral ICC patient undergone curative hepatectomy, while NLR, PLR and LMR are not associated with clinical outcomes of these patients.

\section{Introduction}

Intrahepatic cholangiocarcinoma (ICC) stands as the second most common malignant tumor in liver, however the incidence is growing worldwide during past decades. ${ }^{1,2}$ Up to now, the best choice of curative treatments is surgical resection, while the treatments for unresectable ICC are very limited. ${ }^{3}$ ICC usually grows aggressively without symptom in early stage, resulting in a small proportion of ICC patients who can receive surgery. Furthermore, the prognosis of resectable ICC patient still remains poor and half of them will suffer from recurrence after surgery. ${ }^{4} \mathrm{ICC}$ can be divided into two type: peripheral type and hilar type, based on the location of tumor. Different mechanisms of oncogenesis and clinicopathologic characteristics were shown in two types according to multiple researches. 5

Increasing evidences have shown that inflammation plays a significant role in tumor microenvironment, thus promoting proliferation, angiogenesis and metastasis by various inflammatory cells and cytokines. ${ }^{7}$ In recent years, multiple inflammatory biomarkers were investigated to predict the prognosis of patients with cancer, including neutrophil-to-lymphocyte ratio (NLR), platelet-to-lymphocyte ratio (PLR), lymphocyte-to-monocyte ratio (LMR), systemic immune-inflammation index (SII). Significant results were 
reported in head and neck soft tissue sarcoma, lung cancer, renal cell carcinoma, hepatocellular carcinoma and colorectal cancer. ${ }^{8-10}$

However, significance of these inflammatory biomarkers on prognosis of peripheral ICC patients underwent curative resection has not been fully elucidated. Therefore, this study was performed aiming at evaluating the significance of various inflammatory biomarkers, including NLR, PLR, LMR and SII on patient prognosis in peripheral ICC after curative surgery.

\section{Methods}

\section{Study cohort}

Peripheral ICC patients who underwent curative liver resection between January 2013 and December 2017 at Xiangya hospital, Central South University were retrospectively analyzed. Patients who met the following exclusion criteria were excluded from the study: (1) diagnosis of ICC was not confirmed by pathology; (2) recurrence of ICC; (3) having received an anti-tumor therapy before resection; (4) suffering from infectious diseases before resection; (5) suffering from autoimmune diseases or immunodeficiency diseases; (6) patients who died of postoperative complications or reasons other than ICC; (7) R1 or R2 resection; (8) hilar type of ICC; (9) incomplete clinical data. This study was approved by by the ethics committee of Xiangya Hospital of Central South University. Patient consent was waived because of its retrospective design, and exemption from informed consent did not adversely affect the health and rights of subjects.

\section{Data collection, definitions and follow up}

The medical histories and pathological data were reviewed for basic information, clinical data and tumor characteristics. The 8th American Joint Committee on Cancer (AJCC) Cancer Staging Manual was used to determine the TNM stage. NLR was calculated as neutrophil count $\left(10^{9} / \mathrm{L}\right) /$ lymphocyte count $\left(10^{9} / \mathrm{L}\right)$. PLR was calculated as platelet $\left(10^{9} / \mathrm{L}\right)$ / lymphocyte count $\left(10^{9} / \mathrm{L}\right)$, while LMR as lymphocyte count $\left(10^{9} / \mathrm{L}\right) /$ monocyte count $\left(10^{9} / \mathrm{L}\right)$. And the SIl was defined as platelet $\left(10^{9} / \mathrm{L}\right) \times$ neutrophil/ lymphocyte counts.

Patients were followed up every 3 month after surgery. Blood tests including liver function and serum alpha-fetoprotein level, and imaging examination including abdominal ultrasound, computed tomography, magnetic resonance imaging were performed during follow-up. Recurrence-free survival (RFS) was determined from the first day after surgery to the recurrence of ICC or ICC-related death. Overall survival (OS) was determined from the first day after surgery to the ICC-related death.

\section{Statistical analysis}

SPSS 23.0 (SPSS Company, Chicago, IL) for Windows and Prism software (GraphPad Prism Software, La Jolla, CA) were used to analyze data and realize visualization. The quantitative data were expressed as 
mean \pm standard deviation (SD) and analyzed using independent-sample t test or Mann-Whitney $\mathrm{U}$ test as appropriate. Categorical variables were expressed as frequency (percentage) and analyzed using Chisquare or Fisher exact test as appropriate. The cutoff values were calculated by receiver operating characteristic (ROC) curves. RFS and OS are represented by Kaplan-Meier curves, and differences between groups were analyzed by the log-rank test. Associated factors of RFS and OS were identified using univariate and multivariate Cox's proportional hazard regression. $\mathrm{P}<0.05$ was considered statistically significant.

\section{Results}

\section{Clinicopathologic Characteristics}

128 ICC patients, including 70 males and 58 females, were finally included in this study and the basic characteristics were shown in Table 1. 29.7\% of patients presented hepatitis B virus (HBV) infection, and $28.1 \%$ of patients presented multiple tumors. Proportions of patients with AJCC tumor stage I, II and III were $26.6 \%, 14.8 \%$ and $58.6 \%$, respectively. $35.2 \%$ of patients had liver cirrhosis, while $13.3 \%$ of patients had undermined liver function. The averages of alanine aminotransferase (ALT), aspartate

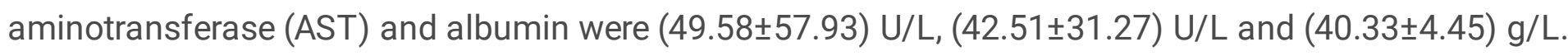
The mean of neutrophil, lymphocyte, monocyte and platelet counts were $(4.70 \pm 1.91) 10^{9} / \mathrm{L}$, $(1.59 \pm 0.49) 10^{9} / \mathrm{L},(0.66 \pm 0.87) 10^{9} / \mathrm{L}$ and $(232.39 \pm 97.68) 10^{9} / \mathrm{L}$, respectively. Furthermore, the mean values of calculated NLR, PLR, LMR and SII were 3.30 $\pm 2.16,156.79 \pm 77.66,3.20 \pm 2.46$ and $793.67 \pm 695.14$, respectively.

\section{Cutoff values of inflammatory biomarkers}

ROC curves were performed on inflammatory biomarkers including NLR, PLR, LMR and SIl to determine appropriate cutoff values, and the results were shown in Figure 1. However, the results showed no significance in NLR, PLR and LMR according to the ROC curves of RFS and OS, while significant results were shown on SII in both RFS $(P=0.035)$ and OS $(P=0.034)$ with areas under ROC curve as $0.63(95 \% \mathrm{Cl}$ : $0.52-0.74)$ and $0.62(95 \% \mathrm{Cl}: 0.51-0.72)$, respectively. Thus, the subsequent analyses were focused on SII with an ideal cutoff value as 1027 according to ROC curves and Youden index.

\section{Survival analyses based on SII}

Survival analyses were performed between SII-low group and SII-high group according to cutoff value of SII, and the results were shown in Figure 2. The median RFS times in SII-low group and SII-high group were 16.4 months and 5.7 months, and the median OS times were 25.2 months and 10.9 months, respectively. The Kaplan-Meier curves revealed statistically significant differences between two groups on both RFS (Pख0.001) and OS (Pख0.001), indicating potential prognostic value of SII in curatively resected ICC patients.

\section{Univariate and multivariate analyses}


To further investigate risk factors affecting RFS and OS of ICC patients, univariate and multivariate analyses were performed for available factors, and the results were shown in Table 2. The univariate and multivariate analyses revealed that multiple tumors, higher AJCC tumor stage, poorer tumor differentiation, higher serum level of carcinoembryonic antigen (CEA) and CA19-9, higher level of SIl were independently associated with both poorer RFS time and OS time. However, no significant result was shown on NLR, PLR or LMR.

\section{Discussion}

It is widely recognized that the systemic inflammation involves in pathogenesis and progression of cancer by various mechanisms including cell proliferation, tissue infiltration and angiogenesis. ${ }^{11,12}$ Inflammatory biomarkers including NLR, PLR, LMR and SIl could present the level of inflammatory and immune response with high availability, thus were suggested as factors to predict the prognosis of patients with cancer. In this study, we investigated the prognostic significance of inflammatory biomarkers in curative resected ICC patients. Our results suggested that SII could effectively predict the prognosis of ICC patients after curative resection, while NLR, PLR and LMR were not associated with prognosis of these patients.

Extensive non-specific inflammatory responses were usually led by allogeneic phenotype of cancer cell, followed by increasing of neutrophils and platelets, and deceasing of lymphocytes. ${ }^{13}$ Neutrophils could secrete TNF-alpha, VEGF and interleukin, thus to promote tumor cell proliferation and angiogenesis. ${ }^{14}$ Meanwhile, TGF-beta, VEGF and platelet derived factors could be secreted by platelets, accelerating differentiation and proliferation of cancer cells, and playing a significant role in adhesion and angiogenesis of tumor tissues. On the other hand, lymphocytes could mediate cytotoxicity and release cytokines, thus presenting antitumor effects as inhibiting growth, proliferation and metastasis of tumor cell. ${ }^{15}$ The decrease of lymphoctyes could lead to lower immune function, progression of tumor, and eventually poor prognosis of patients with tumor. Furthermore, studies showed that activity of lymphocytes could be suppressed by neutrophils. ${ }^{16}$ In addition, monocytes can be recruited to tumor tissues and differentiate into tumor-associated macrophages, which place promoting effects on tumor growth, tumor cell infiltration and angiogenesis. ${ }^{17}$ Thus, the NLR, PLR, LMR and SIl would theoretically be valuable biomarkers for predicting prognosis of cancer, considering all of them could be easily obtained from routine preoperative examinations.

In ICC, the present study showed that SII was the only independent risk factor on RFS and OS of patients. Two previous studies have also investigated the role of SII in OS among ICC patients. ${ }^{18,19}$ Their results both indicated higher SII was associated with poorer patient survival in ICC, which was consistent with our results. However, one of them also showed that NLR had a better significance as a biomarker on ICC patient. The inconsistent results on NLR might be caused by different cohorts because they did not focus on the patients underwent a curative therapy but the whole ICC cohort. 
There were also a few limitations in this study. Firstly, this was a retrospective study with not large sample size. Further prospective, multicenter clinical studies with large cohorts should be performed to validated the values of these inflammatory biomarkers in ICC. Secondly, these inflammatory biomarkers were assessed by single measurements during admission, which might cause uncontrolled bias. Thirdly, some factors which could make an impact on these inflammatory biomarkers, such as smoking and alcoholic, were not fully under control.

\section{Conclusion}

In summary, this study shows that SII is an effective prognostic factor for predicting the prognosis of peripheral ICC patient undergone curative hepatectomy, while NLR, PLR and LMR are not associated with clinical outcomes of these patients.

\section{Abbreviations}

ICC, Intrahepatic cholangiocarcinoma

NLR, Neutrophil-to-lymphocyte ratio

PLR, Platelet-to-lymphocyte ratio

LMR, Lymphocyte-to-monocyte ratio

SII, Systemic immune-inflammation index

RFS, Recurrence-free survival

OS, Overall survival

SD, Standard deviation

ROC, Receiver operating characteristic

HBV, Hepatitis B virus

ALT, Alanine aminotransferase

AST, Aspartate aminotransferase

CEA, Carcinoembryonic antigen

\section{Declarations}

\section{Ethics approval and consent to participate}


The study was approved by the ethics committee of Xiangya Hospital of Central South University. Patient consent was not required to review their medical records by the ethics committee of Xiangya Hospital of Central South University because of its retrospective design, and exemption from informed consent did not adversely affect the health and rights of subjects. This study kept confidentiality of patient data and strictly complied with the Declaration of Helsinki and its later amendments or comparable ethical standards.

\section{Consent for publication}

Not applicable.

\section{Availability of data and material}

All data generated or analyzed during this study are included in this published article.

\section{Competing interests}

The authors declare that they have no competing interests.

\section{Funding}

Not applicable.

\section{Authors' contributions}

All authors made substantive intellectual contributions to this study to qualify as authors. YH conceived of the design of the study. KH modified the design of the study. ZYZ, YFZ, KH performed the study, collected the data, and contributed to the design of the study. ZYZ and YFZ analyzed the data. ZYZ drafted Result, Discussion, Conclusion sections. YFZ and drafted Methods sections. ZYZ, KH, YH edited the manuscript. All authors read and approved the final manuscript. All authors have agreed to be accountable for all aspects of the work in ensuring that questions related to the accuracy or integrity of any part of the work are appropriately investigated and resolved.

\section{Acknowledgements}

Not applicable.

\section{References}

1. Chang K, Chang J, Yen Y. Increasing incidence of intrahepatic cholangiocarcinoma and its relationship to chronic viral hepatitis. Journal of the National Comprehensive Cancer Network: JNCCN. 2009;7(4):423-427.

2. Amini N, Ejaz A, Spolverato G, Kim Y, Herman JM, Pawlik TM. Temporal trends in liver-directed therapy of patients with intrahepatic cholangiocarcinoma in the United States: a population-based 
analysis. J Surg Oncol. 2014;110(2):163-170.

3. Hyder $\mathrm{O}$, Marques $\mathrm{H}$, Pulitano $\mathrm{C}$, et al. A nomogram to predict long-term survival after resection for intrahepatic cholangiocarcinoma: an Eastern and Western experience. Jama Surg. 2014;149(5):432438.

4. Zhang $X$, Beal EW, Bagante $F$, et al. Early versus late recurrence of intrahepatic cholangiocarcinoma after resection with curative intent. The British journal of surgery. 2018;105(7):848-856.

5. Rizvi S, Gores GJ. Pathogenesis, diagnosis, and management of cholangiocarcinoma. Gastroenterology. 2013;145(6):1215-1229.

6. Zhang Z, Zhou Y, Hu K, Wang D, Wang Z, Huang Y. Perineural invasion as a prognostic factor for intrahepatic cholangiocarcinoma after curative resection and a potential indication for postoperative chemotherapy: a retrospective cohort study. Bmc Cancer. 2020;20(1):270.

7. Mantovani A, Allavena P, Sica A, Balkwill F. Cancer-related inflammation. Nature. 2008;454(7203):436-444.

8. Choi E, Kim H, Han I. Elevated preoperative systemic inflammatory markers predict poor outcome in localized soft tissue sarcoma. Ann Surg Oncol. 2014;21(3):778-785.

9. Russo A, Russano M, Franchina T, et al. Neutrophil-to-Lymphocyte Ratio (NLR), Platelet-toLymphocyte Ratio (PLR), and Outcomes with Nivolumab in Pretreated Non-Small Cell Lung Cancer (NSCLC): A Large Retrospective Multicenter Study. Adv Ther. 2020;37(3):1145-1155.

10. Wang D, Bai N, Hu X, et al. Preoperative inflammatory markers of NLR and PLR as indicators of poor prognosis in resectable HCC. Peerj. 2019;7:e7132.

11. Sanford DE, Belt BA, Panni RZ, et al. Inflammatory monocyte mobilization decreases patient survival in pancreatic cancer: a role for targeting the CCL2/CCR2 axis. Clinical cancer research : an official journal of the American Association for Cancer Research. 2013;19(13):3404-3415.

12. Elinav E, Nowarski R, Thaiss CA, Hu B, Jin C, Flavell RA. Inflammation-induced cancer: crosstalk between tumours, immune cells and microorganisms. Nature reviews. Cancer. 2013;13(11):759-771.

13. Xia W, Liu Z, Shen D, Lin Q, Su J, Mao W. Prognostic performance of pre-treatment NLR and PLR in patients suffering from osteosarcoma. World J Surg Oncol. 2016;14:127.

14. Jabłońska E, Kiluk M, Markiewicz W, Piotrowski L, Grabowska Z, Jabłoński J. TNF-alpha, IL-6 and their soluble receptor serum levels and secretion by neutrophils in cancer patients. Arch Immunol Ther Ex. 2001;49(1):63-69.

15. Dunn GP, Old LJ, Schreiber RD. The immunobiology of cancer immunosurveillance and immunoediting. Immunity. 2004;21(2):137-148.

16. Mantovani A. Cancer: Inflaming metastasis. Nature. 2009;457(7225):36-37.

17. Szebeni GJ, Vizler C, Kitajka K, Puskas LG. Inflammation and Cancer: Extra- and Intracellular Determinants of Tumor-Associated Macrophages as Tumor Promoters. Mediat Inflamm. 2017;2017:9294018. 
18. Sellers CM, Uhlig J, Ludwig JM, Stein SM, Kim HS. Inflammatory markers in intrahepatic cholangiocarcinoma: Effects of advanced liver disease. Cancer Med-Us. 2019;8(13):5916-5929.

19. Tsilimigras DI, Moris D, Mehta R, et al. The systemic immune-inflammation index predicts prognosis in intrahepatic cholangiocarcinoma: an international multi-institutional analysis. HPB : the official journal of the International Hepato Pancreato Biliary Association. 2020.

\section{Tables}

Table 1. Clinicopathologic variables of included ICC patients 


\begin{tabular}{|c|c|}
\hline Variables & Values $(n=128)$ \\
\hline Age (years) & $56.19 \pm 9.63$ \\
\hline Male & 70 (54.7) \\
\hline \multicolumn{2}{|l|}{$\mathrm{HBsAg}$} \\
\hline Negative & $90(70.3)$ \\
\hline Positive & $38(29.7)$ \\
\hline Tumor size (cm) & $5.83 \pm 2.85$ \\
\hline \multicolumn{2}{|l|}{ Number of tumors } \\
\hline Single & $92(71.9)$ \\
\hline Multiple & $36(28.1)$ \\
\hline \multicolumn{2}{|l|}{ AJCC tumor stage } \\
\hline 1 & $34(26.6)$ \\
\hline II & $19(14.8)$ \\
\hline III & $75(58.6)$ \\
\hline \multicolumn{2}{|l|}{ Tumor differentiation } \\
\hline Well to moderate & $44(34.4)$ \\
\hline Poor to undifferentiated & $84(65.6)$ \\
\hline \multicolumn{2}{|l|}{ Liver cirrhosis } \\
\hline No & $83(64.8)$ \\
\hline Yes & $45(35.2)$ \\
\hline ALT (U/L) & $49.58 \pm 57.93$ \\
\hline AST (U/L) & $42.51 \pm 31.27$ \\
\hline CEA (ng/ml) & $6.96 \pm 15.93$ \\
\hline CA19-9 (U/ml) & $272.69 \pm 318.33$ \\
\hline CA242 (U/ml) & $75.56 \pm 104.66$ \\
\hline Neutrophil $\left(10^{9} / \mathrm{L}\right)$ & $4.70 \pm 1.91$ \\
\hline Lymphocyte $\left(10^{9} / \mathrm{L}\right)$ & $1.59 \pm 0.49$ \\
\hline Monocyte $\left(10^{9} / \mathrm{L}\right)$ & $0.66 \pm 0.87$ \\
\hline PLT $\left(10^{9} / \mathrm{L}\right)$ & $232.39 \pm 97.68$ \\
\hline
\end{tabular}




\begin{tabular}{|ll|}
\hline Albumin $(\mathrm{g} / \mathrm{L})$ & $40.33 \pm 4.45$ \\
\hline Child-Pugh score & \\
\hline A & $111(86.7)$ \\
\hline B & $17(13.3)$ \\
\hline NLR & $3.30 \pm 2.16$ \\
\hline PLR & $156.79 \pm 77.66$ \\
\hline LMR & $3.20 \pm 2.46$ \\
\hline SII & $793.67 \pm 695.14$ \\
\hline
\end{tabular}

Data are expressed as mean \pm standard deviation or $\mathrm{n}(\%)$. ICC, intrahepatic cholangiocarcinoma; HBsAg, hepatitis B surface antigen; AJCC, American Joint Committee on Cancer; ALT, Alanine aminotransferase; AST, Aspartate aminotransferase; CEA, Carcinoembryonic antigen; PLT, Blood platelet; NLR, neutrophil-tolymphocyte ratio; PLR, platelet-to-lymphocyte ratio; LMR, lymphocyte-to-monocyte ratio; SII, systemic immune-inflammation index.

Table 2. Univariate and multivariate analyses of risk factors with RFS and OS in ICC patients. 


\begin{tabular}{|c|c|c|c|c|}
\hline \multirow[t]{2}{*}{ Variables } & \multicolumn{2}{|l|}{ RFS } & \multicolumn{2}{|l|}{ OS } \\
\hline & $\mathrm{HR}(95 \% \mathrm{Cl})$ & $\begin{array}{l}P \\
\text { value }\end{array}$ & $\mathrm{HR}(95 \% \mathrm{Cl})$ & $\begin{array}{l}P \\
\text { value }\end{array}$ \\
\hline \multicolumn{5}{|l|}{ Univariate analyses } \\
\hline Age (years) ( $₫ 60$ vs. $\leq 60)$ & $\begin{array}{l}0.670(0.440 \\
1.018)\end{array}$ & 0.061 & $\begin{array}{l}0.794(0.514 \\
1.226)\end{array}$ & 0.298 \\
\hline Gender (male vs. female) & $\begin{array}{l}0.899(0.603 \\
1.341)\end{array}$ & 0.603 & $\begin{array}{l}0.763(0.502 \\
1.161)\end{array}$ & 0.207 \\
\hline HBsAg (positive vs. negative) & $\begin{array}{l}0.955(0.618 \\
1.476)\end{array}$ & 0.836 & $\begin{array}{l}0.878(0.555 \\
1.389)\end{array}$ & 0.579 \\
\hline Tumor size $(\mathrm{cm})$ & $\begin{array}{l}1.126(1.053 \\
1.204)\end{array}$ & 0.001 & $\begin{array}{l}1.107(1.035 \\
1.186)\end{array}$ & 0.003 \\
\hline Number of tumors (multiple vs. single) & $\begin{array}{l}1.797(1.168 \\
2.763)\end{array}$ & 0.008 & $\begin{array}{l}1.936(1.246 \\
3.008)\end{array}$ & 0.003 \\
\hline AJCC tumor stage (III vs. I and II) & $\begin{array}{l}1.726(1.135 \\
2.624)\end{array}$ & 0.011 & $\begin{array}{l}1.960(1.250 \\
3.074)\end{array}$ & 0.003 \\
\hline $\begin{array}{l}\text { Tumor differentiation (poor to undifferentiated } \\
\text { vs. well to moderate) }\end{array}$ & $\begin{array}{l}2.173(1.389 \\
3.401)\end{array}$ & 0.001 & $\begin{array}{l}1.971(1.222 \\
3.179)\end{array}$ & 0.005 \\
\hline Liver cirrhosis (presence vs. absence) & $\begin{array}{l}1.483(0.986 \\
2.232)\end{array}$ & 0.059 & $\begin{array}{l}1.335(0.871 \\
2.047)\end{array}$ & 0.185 \\
\hline ALT (U/L) & $\begin{array}{l}0.998(0.994 \\
1.001)\end{array}$ & 0.195 & $\begin{array}{l}0.999(0.995 \\
1.003)\end{array}$ & 0.570 \\
\hline AST (U/L) & $\begin{array}{l}0.996(0.990 \\
1.003)\end{array}$ & 0.273 & $\begin{array}{l}0.999(0.993 \\
1.005)\end{array}$ & 0.815 \\
\hline $\mathrm{CEA}(\mathrm{ng} / \mathrm{ml})$ & $\begin{array}{l}1.020(1.008 \\
1.032)\end{array}$ & 0.001 & $\begin{array}{l}1.027(1.015 \\
1.040)\end{array}$ & 0.001 \\
\hline CA19-9 (U/ml) & $\begin{array}{l}1.002(1.001 \\
1.002)\end{array}$ & 0.001 & $\begin{array}{l}1.002(1.001 \\
1.003)\end{array}$ & $\begin{array}{l}\square \\
0.001\end{array}$ \\
\hline CA242 (U/ml) & $\begin{array}{l}1.005(1.003 \\
1.007)\end{array}$ & 0.001 & $\begin{array}{l}1.005(1.003 \\
1.007)\end{array}$ & $\begin{array}{l}\square \\
0.001\end{array}$ \\
\hline NLR & $\begin{array}{l}1.018(0.947 \\
1.096)\end{array}$ & 0.625 & $\begin{array}{l}1.033(0.960 \\
1.112)\end{array}$ & 0.387 \\
\hline PLR & $\begin{array}{l}1.003(1.000 \\
1.005)\end{array}$ & 0.021 & $\begin{array}{l}1.003(1.001 \\
1.006)\end{array}$ & 0.011 \\
\hline LMR & $\begin{array}{l}1.039(0.943 \\
1.146)\end{array}$ & 0.435 & $\begin{array}{l}1.019(0.903 \\
1.151)\end{array}$ & 0.757 \\
\hline SII (SII-low group vs. SII-high group) & $\begin{array}{l}2.352(1.519 \\
3.641)\end{array}$ & $\begin{array}{l}\text { ? } \\
0.001\end{array}$ & $\begin{array}{l}2.340(1.484, \\
3.689)\end{array}$ & $\begin{array}{l}0.001 \\
0.01\end{array}$ \\
\hline
\end{tabular}




\begin{tabular}{|c|c|c|c|c|}
\hline Albumin $(\mathrm{g} / \mathrm{L})$ & $\begin{array}{l}0.979(0.936 \\
1.023)\end{array}$ & 0.347 & $\begin{array}{l}0.969 \text { (0.924, } \\
1.017)\end{array}$ & 0.203 \\
\hline Child-Pugh score (B vs. A) & $\begin{array}{l}0.996(0.564 \\
1.757)\end{array}$ & 0.988 & $\begin{array}{l}1.286(0.725 \\
2.279)\end{array}$ & 0.389 \\
\hline \multicolumn{5}{|l|}{ Multivariate analyses } \\
\hline Tumor size $(\mathrm{cm})$ & $\begin{array}{l}1.030(0.953, \\
1.113)\end{array}$ & 0.456 & $\begin{array}{l}0.976(0.899 \\
1.060)\end{array}$ & 0.563 \\
\hline Number of tumors (multiple vs. single) & $\begin{array}{l}1.849(1.168 \\
2.928)\end{array}$ & 0.009 & $\begin{array}{l}2.017(1.274 \\
3.192)\end{array}$ & 0.003 \\
\hline AJCC tumor stage (III vs. I and II) & $\begin{array}{l}1.599(1.018 \\
2.511)\end{array}$ & 0.042 & $\begin{array}{l}1.982(1.207 \\
3.255)\end{array}$ & 0.007 \\
\hline $\begin{array}{l}\text { Tumor differentiation (poor to undifferentiated } \\
\text { vs. well to moderate) }\end{array}$ & $\begin{array}{l}2.355(1.444 \\
3.840)\end{array}$ & 0.001 & $\begin{array}{l}1.865(1.093 \\
3.182)\end{array}$ & 0.022 \\
\hline CEA (ng/ml) & $\begin{array}{l}1.022(1.008, \\
1.037)\end{array}$ & 0.003 & $\begin{array}{l}1.033(1.017 \\
1.049)\end{array}$ & $\begin{array}{l}0.001 \\
0.001\end{array}$ \\
\hline CA19-9 (U/ml) & $\begin{array}{l}1.001(1.000 \\
1.002)\end{array}$ & 0.034 & $\begin{array}{l}1.002(1.001 \\
1.003)\end{array}$ & 0.001 \\
\hline CA242 (U/ml) & $\begin{array}{l}1.001(0.998, \\
1.004)\end{array}$ & 0.552 & $\begin{array}{l}0.999(0.996 \\
1.003)\end{array}$ & 0.712 \\
\hline PLR & $\begin{array}{l}0.998(0.995 \\
1.002)\end{array}$ & 0.327 & $\begin{array}{l}0.998(0.995 \\
1.002)\end{array}$ & 0.316 \\
\hline SII (SII-high group vs. SII-low group) & $\begin{array}{l}2.368(1.279, \\
4.386)\end{array}$ & 0.006 & $\begin{array}{l}2.454(1.278 \\
4.712)\end{array}$ & 0.007 \\
\hline
\end{tabular}

$\mathrm{HR}$, hazard ratio; $\mathrm{Cl}$, confidence interval; ICC, intrahepatic cholangiocarcinoma; RFS, recurrence-free survival; OS, overall survival; HBsAg, hepatitis B surface antigen; AJCC, American Joint Committee on Cancer; ALT, Alanine aminotransferase; AST, Aspartate aminotransferase; CEA, Carcinoembryonic antigen; NLR, neutrophil-to-lymphocyte ratio; PLR, platelet-to-lymphocyte ratio; LMR, lymphocyte-to-monocyte ratio; SII, systemic immune-inflammation index.

\section{Figures}


a

ROC curve of NLR

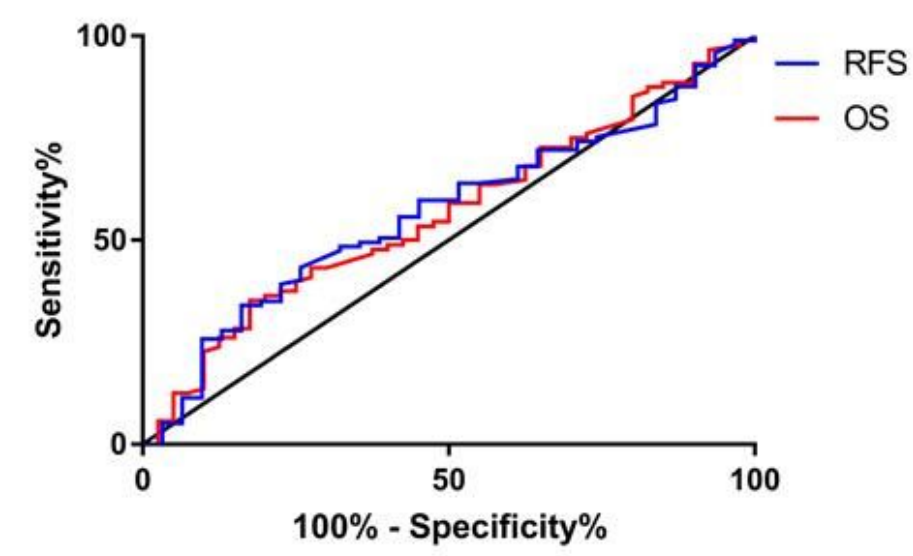

C

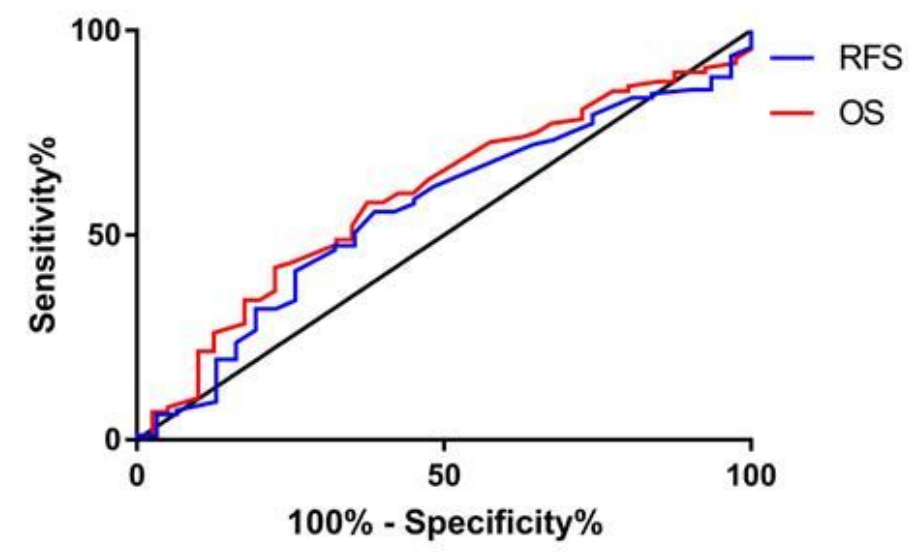

b ROC curve of PLR

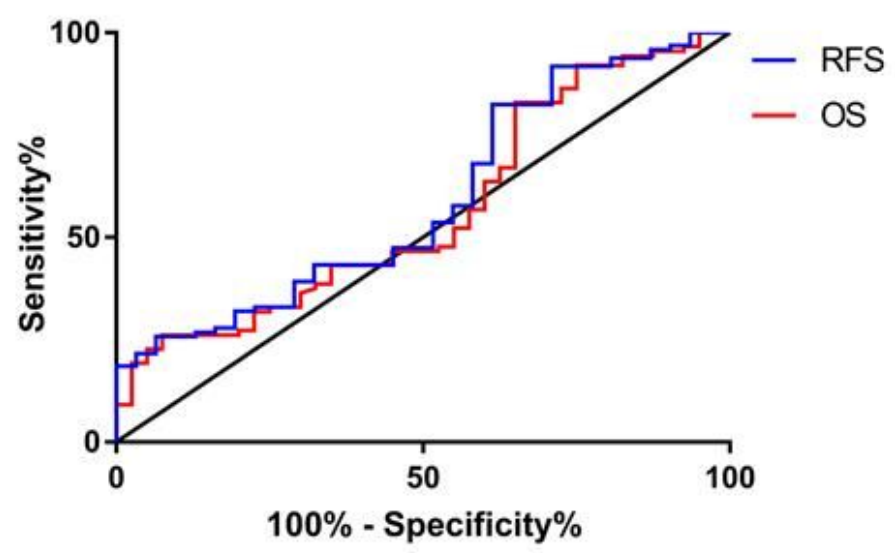

d

ROC curve of SII

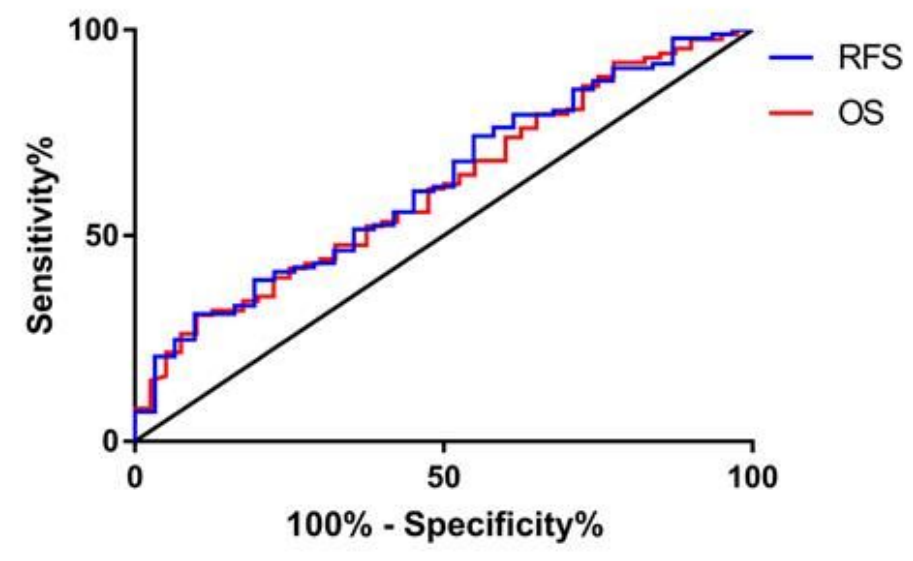

Figure 1

ROC curves of NLR(a), PLR (b), LMR (c) and SII (d) on RFS and OS. a The AUC for RFS and OS were 0.569 (95\% $\mathrm{Cl}=0.459-0.679, \mathrm{P}=0.250)$, and $0.565(95 \% \mathrm{Cl}=0.461-0.669, \mathrm{P}=0.239) . \mathrm{b}$ The AUC for RFS and OS were $0.592(95 \% \mathrm{Cl}=0.477-0.707, \mathrm{P}=0.125)$, and $0.568(95 \% \mathrm{Cl}=0.460-0.675, \mathrm{P}=0.222)$. $\mathrm{c}$ The AUC for RFS and OS were $0.561(95 \% \mathrm{Cl}=0.447-0.674, \mathrm{P}=0.310)$, and $0.597(95 \% \mathrm{Cl}=0.493-0.701, \mathrm{P}=0.079)$. $\mathrm{d}$ The AUC for RFS and OS were $0.626(95 \% \mathrm{Cl}=0.517-0.736, \mathrm{P}=0.035)$, and $0.617(95 \% \mathrm{Cl}=0.515-0.719, \mathrm{P}=0.034)$. ROC, receiver operating characteristic; AUC, area under curve; NLR, neutrophil-to-lymphocyte ratio; PLR, plateletto-lymphocyte ratio; LMR, lymphocyte-to-monocyte ratio; SII, systemic immune-inflammation index; RFS, recurrence free survival; OS, overall survival. 
a

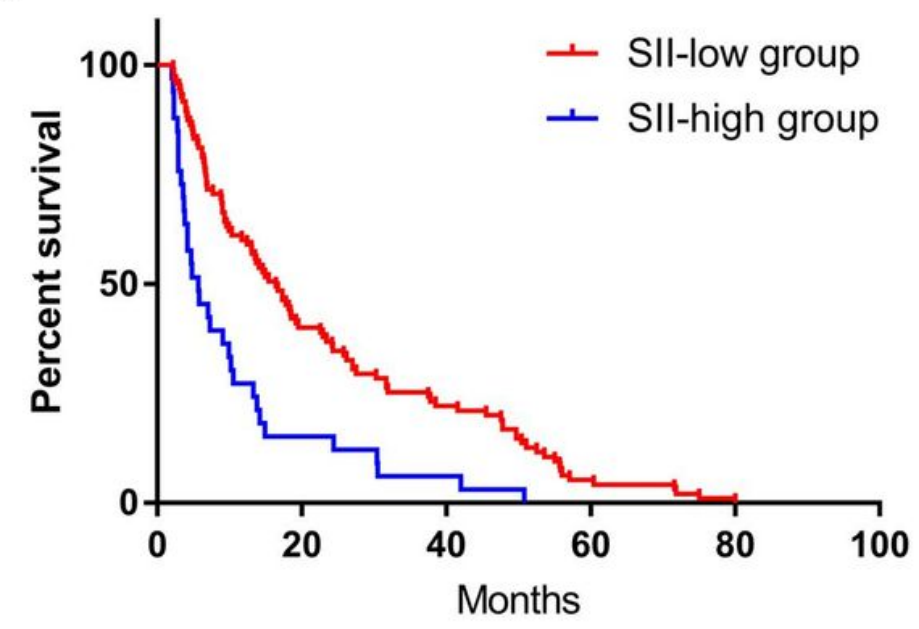

b

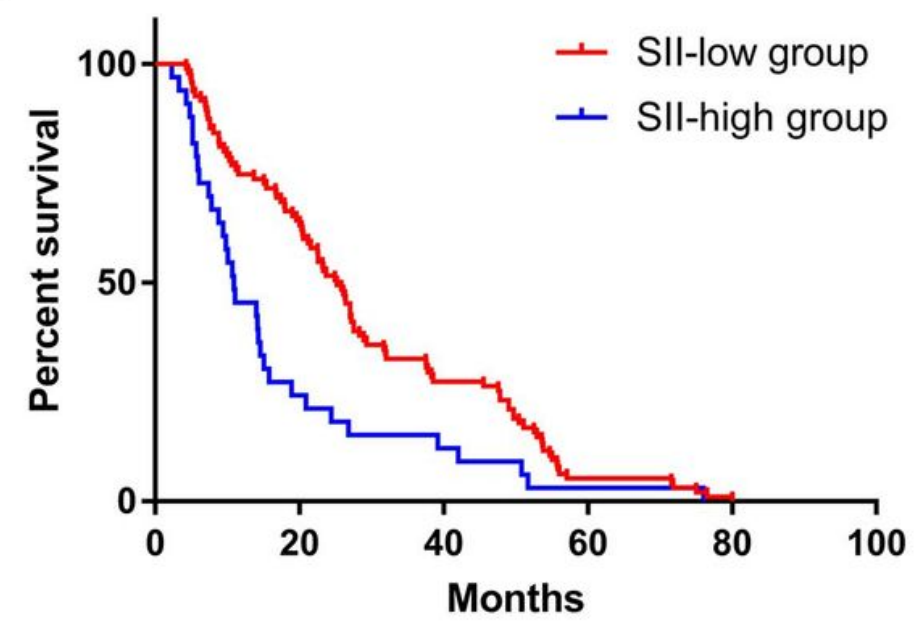

Figure 2

Comparisons between SII-low group and SII-high group using Kaplan-Miere curves on RFS (a) and OS (b). Better survival data were showed in SII-low group on both RFS $(P<0.001)$ and OS $(P<0.001)$. SIl, systemic immune-inflammation index; RFS, recurrence free survival; OS, overall survival. 